media thickness (CIMT), electrocardiography (ECG) and echocardiography with assessment of ejection fraction (EF) and diastolic dysfunction (E/A ratio).

Results: The significant differences between male vs female RA patients included: higher mean values of cIMT $[0,93(0,19)$ vs $0,80(0,22) \mathrm{mm}, \mathrm{p}=0,04]$, atherogenic index $[4,2(1,4)$ vs $3,5(1,0), p=0,03]$ and SCORE $[5,7(3,7)$ vs 2,8 $(2,7), \mathrm{p}<0001]$; as well as lower concentration of HDL-cholesterol [(50,2 (12) vs $\left.59^{14,6} \mathrm{mg} / \mathrm{dl}, \mathrm{p}=0,04\right]$ and NT-proBNP $[66,6(61,2)$ vs $106,8(61,5) \mathrm{pg} / \mathrm{ml}, \mathrm{p}=0006]$. The mean values of age, disease duration, DAS28, C-reactive protein, body mass index, BP, QTc, E/A and EF were not significantly different in male and female patients with RA of low activity.

In the control group no significant differences were observed between male and female subjects, when considering: age, cIMT, BP, QTc, EF, E/A

All the male RA patients had features of subclinical or advanced atherosclerosis (cIMT $\geq 0.6 \mathrm{~mm}$ ), there were no male patients with normal cIMT $(<0,6 \mathrm{~mm})$. In controls normal cIMT was found in $5(33,3 \%)$ and subclinical atherosclerosis in 10 $(66,7 \%)$, there was no control subject with advanced atherosclerosis $(p=0,01)$. The mean age of patients and controls did not differ significantly.

Conclusions: The results of the study suggest an unfavourable $\mathrm{CV}$ risk profile in male RA patients with low disease activity. The higher CV risk was observed in male RA patients in comparison with both controls of comparable age, as well as with female RA patients of comparable age, disease duration and activity. It seems that the male gender contributes considerably to $\mathrm{CV}$ risk in the period of low RA activity.

Disclosure of Interest: None declared

DOI: 10.1136/annrheumdis-2018-eular.3142

\section{AB0209 OPTIMISATION OF ULTRASONOGRAPHIC EXAMINATION FOR THE DIAGNOSIS OF EROSIVE RHEUMATOID ARTHRITIS VERSUS EROSIVE OSTEOARTHRITIS WITH RADIOGRAPHY CONSIDERED AS GOLD STANDARD}

C. Roux ${ }^{1}$, F. Gandjbakhch ${ }^{2}$, A. Pierreisnard ${ }^{2}$, M. Couderc ${ }^{3}$, C. Lukas $^{4}$, R. Masri ${ }^{5}$, J.-P. Sommier ${ }^{1}$, I. Clerc-Urmes ${ }^{6}$, C. Baumann ${ }^{6}$, I. Chary-Valckenaere ${ }^{1}$,

D. Loeuille ${ }^{1} .{ }^{1}$ Rheumatology, University Hospital of Nancy, Vandoeuvre-lès-Nancy; ${ }^{2}$ Rheumatology, Academic Hospital Pitie Salpêtrière, Paris; ${ }^{3}$ Rheumatology, University Hospital of Clermont- Ferrand, Clermont- Ferrand; ${ }^{4}$ Rheumatology, University Hospital of Lapeyronie, Montpellier, ${ }^{5}$ Rheumatology, University Hospital of Nancy, Vandoeuvre-lès-Nancy; ${ }^{6}$ Platform of Clinical Research Support PARC, University Hospital of Nancy, Vandoeuvre-lès-Nancy, France

Background: Rheumatoid arthritis (RA) is the most prevalent chronic inflammatory joint disease ${ }^{1,2}$ responsible for structural damage. Radiography $(R X)$ is considered as the gold standard for visualising and quantifying bone lesions in RA. ${ }^{3}$ Musculoskeletal ultrasound (US) is booming in clinical practice for the diagnosis of RA. US can detect more erosions than RX at the joint level, especially at an early stage of the disease. ${ }^{4}$

Objectives: To determine thresholds and better scenarios for the diagnosis of erosive RA by US in RA and osteoarthritic (OA) patients.

Methods: Patients fulfiling ACR 1987 and/or ACR/EULAR 2010 criteria for RA or hand OA criteria were prospectively included. A modified Sharp erosion score was assessed by two blinded readers and one adjudicator for discordant cases (number of eroded joints $\leq$ three). Erosions in US were scored on six bilateral joints (MCP2-3, 5; MTP2-3,5) with a four-grade scale.

Results: A total of 168 patients were included: 122 RA (32 early RA $<2$ years; 90 late $R A \geq 2$ years); 46 OA patients. On RX: 42 RA patients ( 6 early; 36 late) and 5 OA patients were eroded according to ACR/EULAR 2013 criteria (sensitivity: $34.4 \%$, specificity: $89.1 \%$ ). On US, 95 RA patients (21 early; 78 late) and 12 OA patients were eroded. Considering at least two joint facets eroded (threshold 1) or at least one joint facet eroded at grade 2 (threshold 2), sensitivities were good $(68 \%-$ $72.1 \%)$ and specificities excellent $(89.1 \%-100 \%)$. With only six targeted joint facets examined, 73 and 74 patients were classified as erosive RA with threshold 1 and 2 with good sensitivities $(59.8 \%-60.0 \%)$ and excellent specificities $(95.6 \%-$ $100 \%)$ respectively. For all scenarios, agreement between RX and US for the diagnosis of erosive RA was excellent ( $88.1 \%$ to $92.8 \%$ ).

Conclusions: US erosion assessment of six targeted joint facets permitted to detect 1.7 times more erosive RA patients than RX in late and early RA.

\section{REFERENCES:}

[1] Guillemin F, et al. Prevalence of rheumatoid arthritis in France: 2001. Ann Rheum Dis. 2005 Oct;64(10):1427-30.

[2] Alamanos $Y$, et al. Incidence and prevalence of rheumatoid arthritis, based on the 1987 American College of Rheumatology criteria: a systematic review. Semin Arthritis Rheum. 2006 Dec;36(3):182-8.

[3] Baillet A, et al. Comparison of the efficacy of sonography, magnetic resonance imaging and conventional radiography for the detection of bone erosions in rheumatoid arthritis patients: a systematic review and metaanalysis. Rheumatol Oxf Engl. 2011 Jun;50(6):1137-47.
[4] Wakefield RJ, et al. The value of sonography in the detection of bone erosions in patients with rheumatoid arthritis: a comparison with conventional radiography. Arthritis Rheum. 2000 Dec;43(12):2762-70.

Disclosure of Interest: None declared

DOI: 10.1136/annrheumdis-2018-eular.2838

\section{AB0210 CLINICAL AND MUSCULOSKELETAL ULTRASOUND ASSESSMENT OF THERAPEUTIC RESPONSE TO TOFACITINIB IN PATIENTS WITH RHEUMATOID ARTHRITIS: REAL-WORLD CLINICAL EXPERIENCE FROM A SINGLE CENTRE IN HONG KONG}

C.K.-L. Yu. Hong Kong Autoimmune and Rheumatic Diseases Certre, Hong Kong, Hong Kong

Background: Increasingly, musculoskeletal ultrasound (MSUS) has been demonstrated as an effective method for monitoring disease activity and joint damage in patients with rheumatoid arthritis (RA).

Objectives: The objective of this single-centre, 12 week study was to evaluate the effects of tofacitinib therapy in Chinese patients with RA using clinical, laboratory and sonographic assessments, with the view to identifying factors that may predict response to tofacitinib. Furthermore, the study sought to determine whether MSUS would be comparable to conventional techniques for monitoring disease activity in RA

Methods: Patients with RA ( $n=18$ ) were treated with tofacitinib $5 \mathrm{mg}$ bd for 12 weeks. Clinical, laboratory and ultrasound examinations were conducted at baseline (T0), and weeks 4 (T1), 8 (T2) and 12 (T3). Erythrocyte sedimentation rate, C reactive protein, physician and patient visual analogue scale for disease activity, number of tender and swollen joints, Clinical Disease Activity Index (CDAI), Simple Disease Activity Index (SDAI) and Disease Activity Score in 28 joints (DAS28) were assessed and compared. MSUS was performed bilaterally in all metacarpophalangeal, interphalangeal, wrist and knee joints. A semi-quantitative score (03) was used to indicate the presence of a localised inflammatory process and/or structural damage. The cumulative total was used as an indicator of global change in each joint (single joint score). The sum of the single joint scores was used as an indicator of overall polyarticular involvement in each patient (total joint score).

Results: Of the 18 patients recruited into the study, all 18 were examined at T0, $\mathrm{T} 1$ and $\mathrm{T} 2$, and 17 patients were evaluated at T3. All clinical and laboratory measures, as well as MSUS scores, were significantly reduced during follow-up. There was a significant correlation between MSUS scores and conventional (clinical and laboratory) measures of disease activity. Correlation coefficients between the techniques and factors potentially predicting response to tofactinib will be reported.

Conclusions: A positive response to tofacitinib treatment was shown by both MSUS examination and clinical evaluation, with good correlation between the methods. In a busy, every-day, clinical-practice setting in Hong Kong, MSUS was found to be a useful tool for monitoring and following-up the effects of biologic therapy in RA, for the assessment of both inflammatory and destructive changes.

Disclosure of Interest: None declared

DOI: 10.1136/annrheumdis-2018-eular.5054

\section{AB0211 THE RELATIONSHIP BETWEEN THE ELEVATED SERUM IMMUNOGLOBULIN G4 LEVEL AND DISEASE ACTIVITY IN PATIENTS WITH RHEUMATOID ARTHRITIS}

C.-N. Son, H.-J. Jeong, J.-N. Chae, J.-M. Kim, S.-H. Kim. Internal Medicine, Keimyung University, Daegu, Korea, Republic of Ireland

Background: High levels of serum immunoglobulin G4 (IgG4) would comprise a useful diagnostic tool in lgG4-related disease, but little information is available about IgG4 in conditions other than IgG4-related disease, including rheumatic diseases. Previous studies indicate that the elevated serum IgG4 in rheumatoid arthritis (RA) is common and disproportional to total lgG.

Objectives: The aim of study is to evaluate the level of serum lgG4 and lgG4/total IgG ratio in patients with $R A$

Methods: Ninety-six patients with RA and one hundred and thirty-five non-RA controls were enrolled between March 2014 and July 2017. All samples were collected before the treatments. The levels of Serum total $\lg G$ and $\lg G 4$ were deter mined by nephelometric assay. The cut-off value of serum IgG4 was $135 \mathrm{mg} / \mathrm{dL}$. Data on clinical variables and disease activity markers, such as numbers of tender and swollen joints, levels of acute phase reactants and disease activity score 28 (DAS28) were recorded in RA patients. We compared the levels of serum IgG4 and the ratio of $\operatorname{lgG} 4 /$ total $\operatorname{lgG}$ in rheumatoid arthritis with healthy controls and other rheumatic diseases. This study also investigated the difference the relationship between levels of serum IgG4 and disease activity in RA. 